\title{
ANALISIS FAKTOR-FAKTOR YANG MEMENGARUHI KONTRAKTOR UTAMA DALAM PEMILIHAN SUBKONTRAKTOR PADA PELAKSANAAN PROYEK KONSTRUKSI
}

\author{
Erwin Tanuwijaya ${ }^{1}$ dan Jane Sekarsari $\mathbf{T}^{2}$ \\ ${ }^{1}$ Program Studi Sarjana Teknik Sipil, Universitas Tarumanagara, Jl. Letjen S. Parman No.1 Jakarta \\ Email:erwiintan@gmail.com \\ ${ }^{2}$ Program Studi Sarjana Teknik Sipil, Universitas Tarumanagara, Jl. Letjen S. Parman No.1 Jakarta \\ Email: tamtana.js@gmail.com
}

\begin{abstract}
ABSTRAK
Kerjasama antara kontraktor utama dan subkontraktor dilakukan untuk melaksanakan pekerjaan konstruksi agar dapat terlaksana sesuai dengan perencanaan. Keberhasilan suatu pekerjaan tidak lepas dari partisipasi subkontraktor yang mampu bekerja dengan baik dan bertanggung jawab terhadap pengawasan dalam bidang konstruksi. Sehiggga diperlukan hubungan yang baik antar kedua pihak yang dapat menghambat jalannya pelaksanaan proyek konstruksi. Penelitian sebelumnya telah membahas pemilihan subkontraktor, namun masih terdapat beberapa faktor yang belum dianalisa, serta penelitian tersebut dilakukan pada daerah di luar Jakarta. Pada penelitian ini akan dilakukan analisis mengenai faktor-faktor yang memengaruhi pemilihan subkontraktor dengan menambah beberapa faktor yang berasal dari studi pustaka serta wawancara pada proyek yang berada di wilayah Jakarta, sehingga dapat membantu kontraktor dalam memilih subkontraktor berdasarkan kriteria tertentu. Dari hasil studi pustaka dan wawancara diperoleh faktor-faktor berupa profil perusahaan, administrasi, perngalaman perusahaan, kemampuan teknis, keuangan, kondisi sosial, waktu dan mutu. Penelitian ini dilakukan dengan menyebarkan kuesioner pada pihak-pihak kontraktor yang termasuk dalam panitia tender. Analisis mengunakan metode analisis faktor dan dilakukan pengujian validitas yang meliputi KMO (Kaiser Meyer Olkin), Bartlett serta pengujian MSA (Measure of Sampling Adequacy) kemudian pengujian reliabilitas. Hasil analisis studi ini terdapat 6 kelompok faktor yaitu kinerja perusahaan, prestasi perusahaan, sumber daya, informasi, marketing, dan hubungan kerjasama. Dan faktor-faktor yang paling memengaruhi adalah kesesuaian masa kerja subkontraktor dengan jadwal pelaksanaan, lama pengalaman melaksanakan proyek serupa, sumber daya yang dimiliki, frekuensi komunikasi, harga penawaran yang kompetitif, lamanya hubungan kerjasama yang terjalin.
\end{abstract}

Kata kunci: kontraktor utama, pemilihan subkontraktor, analisis faktor.

\section{PENDAHULUAN}

\section{Latar Belakang}

Kontraktor merupakan salah satu badan usaha yang dikontrak atau disewa untuk menjalankan proyek konstruksi berdasarkan isi kontrak yang dimenangkannya dari pihak pemilik proyek. Dalam pelaksanaan proyek konstruksi terdapat banyak pekerjaan yang harus diselesaikan sesuai dengan durasi proyek yang sudah ditetapkan, sehingga kontraktor utama membutuhkan jasa subkontraktor sebagai mitra untuk turut membantu dalam penyelesaian suatu pekerjaan sehingga dapat meminimalisir resiko kegagalan.

Ketepatan dalam pemilihan subkontraktor yang dilakukan oleh penanggung jawab proyek harus sangat diperhatikan, agar tidak terjadi perselisihan antar kedua pihak yang dapat menghambat jalannya pelaksanaan proyek konstruksi. Keberhasilan suatu pekerjaan tidak lepas dari partisipasi subkontraktor yang mampu bekerja dengan baik dan bertanggung jawab terhadap pengawasan sebagai pekerja dalam bidang konstruksi.

Berkaitan dengan hubungan kontaktor dengan subkontraktor, maka perlu dilakukan analisis faktor-faktor yang memengaruhi kontraktor dalam pemilihan subkontraktor serta faktor yang paling dominan. Agar pihak kontraktor maupun subkontraktor dapat mengambil langkah-langkah yang signifikan dalam pelaksanaan pekerjaan konstruksi.

Pada penelitian sebelumnya yang dilakukan oleh Maitimu (2014), Messah (2012) telah membahas mengenai pemilihan subkontraktor oleh kontraktor. Namun masih terdapat beberapa faktor yang belum dianalisa serta penelitian tersebut dilakukan pada daerah di luar Jakarta. Sehingga pada penelitian ini akan dilakukan analisis 
mengenai faktor - faktor yang memengaruhi pemilihan subkontraktor dengan menambah beberapa faktor yang berasal dari studi pustaka serta wawancara pada proyek yang berada di wilayah Jakarta.

\section{Tujuan Penelitian}

Berdasarkan rumusan masalah diatas, maka maksud dan tujuan dari penelitan ini adalah:

1. Mendapatkan faktor-faktor yang memengaruhi kontraktor utama dalam memilih subkontraktor pada proyek konstruksi di Jakarta.

2. Mendapatkan faktor yang paling memengaruhi kontraktor utama dalam memilih subkontraktor pada proyek konstruksi di Jakarta.

\section{Proyek Konstruksi}

Menurut Pudjosumarto (dalam Hendriko, 2016), proyek konstruksi adalah suatu kegiatan yang berlangsung dalam waktu yang terbatas dengan sumber daya tertentu untuk mendapatkan hasil konstruksi dengan standar kualitas yang baik.

Nasrul (dalam Hendriko, 2016) mendefinisikan proyek konstruksi adalah suatu rangkaian kegiatan yang hanya satu kali dilakukan dan umumnya berjangka pendek serta jelas waktu awal dan akhirnya. Dalam rangkaian kegiatan tersebut ada suatu proses mengolah sumber daya proyek menjadi satu hasil karya berupa bangunan.

Proyek konstruksi merupakan suatu rangkaian kegiatan yang saling berkaitan untuk mencapai tujuan tertentu (bangunan/konstruksi) dalam Batasan waktu, biaya dan mutu tertentu. Proyek konsruksi selalu memerlukan sumber daya yaitu manusia, bahan bangunan, peralatan, metode pelaksanaan, uang, informasi dan waktu.

\section{Kontraktor}

Menurut Resmal (2014) kontraktor adalah perusahaan yang melakukan kontrak kerja dengan orang atau perusahaan lain untuk memasok barang atau menyelesaikan jasa konstruksi. Menurut Ervianto (2005) kontraktor adalah orang/badan yang menerima pekerjaan dan menyelenggarakan pelaksanaan pekerjaan sesuai biaya yang telah ditetapkan berdasarkan gambar rencana dan peraturan serta syarat-syarat yang ditetapkan.

Kontraktor bertanggung jawab secara langsung pada pemilik proyek (owner) dan dalam melaksanakan pekerjaannya diawasi oleh tim pengawas dari owner serta dapat berkonsultasi secara langsung dengan tim pengawas terhadap masalah yang terjadi dalam pelaksanaan. Perubahan desain harus segera dikonsultasikan sebelum pekerjaan dilaksanakan.

\section{Subkontraktor}

Fahrurrazi (2002) menyebutkan subkontraktor adalah subpelaksana konstruksi yang merupakan mitra kerja perusahaan yang diikat dengan surat perjanjian pemborong pekerjaan. Sedangkan menurut Clough (2005) subkontraktor adalah sebuah perusahaan konstruksi yang melakukan kontrak dengan kontraktor utama untuk melakukan beberapa bagian kegiatan pekerjaan kontaktor utama.

Pada pelaksanaan suatu konstruksi, peran subkontraktor tidak bisa dihilangkan. Sehingga tanggung jawab dari subkontraktor harus sangat diperhatikan. Subkontraktor dibedakan menjadi 2 macam, yaitu:

1. Subkontraktor yang menyediakan pekerja saja, yaitu subkontraktor yang dalam melaksanakan pekerjaan bangunan/konstruksi hanya menyediakan tenaga kerja dan alat kerja konstruksi (traktor, mesin pancang, dan sebagainya), sedangkan bahan bangunan disediakan oleh perusahaan yang mensubkontrakkan.

2. Subkontraktor yang menyediakan pekerja dan material konstruksi, yaitu subkontraktor yang menerima dan melaksanakan sebagian/seluruh pekerjaan/proyek konstruksi yang disubkontrakkan secara penuh oleh perusahaan kontraktor, artinya penyediaan bahan bangunan dan tenaga kerja seluruhnya adalah tanggung jawab subkontraktor.

\section{Hubungan Kontraktor dengan Subkontraktor}

Saputra (2017) menyatakan hubungan kerja antara perusahaan kontraktor dan subkontraktor dilaksanakan untuk mengatasi kesulitan yang muncul di lapangan agar dapat mencapai keberhasilan proyek.

Hubungan kerja kontraktor dan subkontraktor dilaksanakan untuk saling menguntungkan (win-win solution). Beberapa keuntungan yang didapat adalah meningkatkan hubungan relasi, mengurangi dan membagi resiko, mengurangi biaya dan mengurangi sumber daya. 
Pemilihan subkontraktor oleh kontraktor utama dilakukan dengan 2 cara yakni:

1. Penunjukan langsung, bila subkontraktor sudah diikat dengan kesepakatan pada saat proses tender atau bila diperkirakan subkontraktor tersebut yang paling memenuhi syarat.

2. Tender, bila calon subksontraktor lebih dari 1 dan belum dikenal secara jelas.

\section{Proses Pemilihan Subkontraktor}

Menurut Rasono (2017) dalam mengeksekusi sebuah proyek tentu tidak lepas dari proses pemilihan subkontraktor, untuk mendapatkan subkontraktor yang memenuhi kriteria tentu diperlukan tahapan-tahapan agar semua faktor terpenuhi. Sepanjang semua kriteria diterapkan secara konsisten maka akan didapat subkontraktor yang dapat diandalkan sesuai keahliannya.

Berikut ini proses kualifikasi dan evaluasi subkontraktor yaitu:

1. Prakualifikasi (Pre Qualification)

2. Evaluasi Penawaran (Bid Evaluation)

3. Penilaian Kinerja Subkontraktor (Subcontractor Performance)

\section{Aspek Pemilihan Subkontraktor}

Terdapat 6 aspek yang patut untuk diidentifikasikan dalam pemilihan subkontraktor yaitu:

1. Aspek Umum.

2. Aspek Keuangan

3. Aspek Teknis

4. Aspek Manajerial

5. Aspek Keselamatan Kerja

6. Aspek Reputasi Perusahaan

\section{METODOLOGI PENELITIAN}

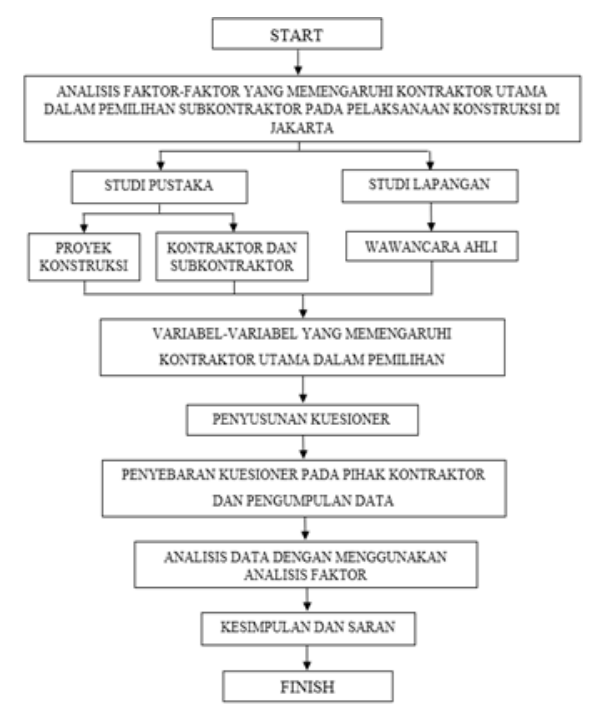

Gambar 1. Diagram penelitian

Data yang diperoleh dari kuisioner masih dalam data kuantitatif maka harus diubah menjadi data kualitatif dengan menggunakan skala likert, dimana nilai dari setiap variabel kuisioner akan berkisar antara 1 sampai 5.

Tabel 1. Tabel Skala Likert

\begin{tabular}{cc}
\hline Skala & Keterangan \\
\hline 1 & Tidak Berpengaruh \\
\hline 2 & Kurang Berpengaruh \\
\hline 3 & Cukup Berpengaruh \\
\hline 4 & Berpengaruh \\
\hline 5 & Sangat Berpengaruh \\
\hline
\end{tabular}




\section{Faktor-faktor Pemilihan Subkontraktor}

Berdasarkan hasil studi pustaka dan wawancara yang berhubungan dengan faktor-faktor pemilihan subkontraktor oleh kontraktor utama diperoleh faktor-faktor yang dapat dilihat pada tabel 2 berikut.

Tabel 2. Faktor-faktor pemilihan subkontraktor

\begin{tabular}{|c|c|}
\hline Kode & Faktor-Faktor Pemilihan Subkontraktor \\
\hline \multicolumn{2}{|r|}{ Kelompok A : Profil Perusahaan } \\
\hline A.1 & $\begin{array}{l}\text { Data dan informasi perusahaan (Misalnya } \\
\text { kelengkapan data perusahaan) }\end{array}$ \\
\hline A.2 & Lokasi Perusahaan \\
\hline A.3 & Kelengkapan dokumen (Misalnya dokumen kontrak) \\
\hline A.4 & Keanggotaan dalam asosiasi konstruksi \\
\hline \multicolumn{2}{|r|}{ Kelompok B : Administrasi } \\
\hline B.1 & Jenis penawaran \\
\hline B.2 & Cara pembayaran kerja \\
\hline B.3 & Harga penawaran yang kompetitif \\
\hline B.4 & Strukfur Organisasi \\
\hline B.5 & Jumlah personil yang ditawarkan \\
\hline \multicolumn{2}{|r|}{ Kelompok C : Pengalaman Perusahaan } \\
\hline C.1 & Prestasi melaksanakan proyek \\
\hline C.2 & Lama pengalaman melaksanakan proyek serupa \\
\hline C.3 & Lamanya hubungan kerjasama yang terjalin \\
\hline \multicolumn{2}{|r|}{ Kelompok D : Kemampuan Teknis } \\
\hline D.1 & $\begin{array}{l}\text { Keahlian personil (Misalnya memiliki lisensi SKA } \\
\text { dan SKT) }\end{array}$ \\
\hline D.2 & Sumber daya yang dimiliki (Misalnya kepemilikan \\
\hline D.3 & Memiliki peralatan dan fasilitas yang sesuai \\
\hline D.4 & $\begin{array}{l}\text { Mengutamakan keamanan dan keselamatan kerja } \\
\text { selama pelaksanaan proyek (Sertifikasi SMK3) }\end{array}$ \\
\hline D.5 & Metode kerja \\
\hline \multicolumn{2}{|c|}{ Kelompok E : Keuangan } \\
\hline E.1 & Kemampunan finausial subkontraktor \\
\hline E.2 & Ketaatan subkontraktor dalam membayar pajak \\
\hline E.3 & Adanya jaminan asturansi terhadap pekerja \\
\hline \multicolumn{2}{|r|}{ Kelompok F : Kondisi Sosial } \\
\hline F.1 & $\begin{array}{l}\text { Komunikasi yang baik (Misalnya mudah dalam } \\
\text { hubungan komunikasi antar pekerja sehingga tidak } \\
\text { terjadi kesalahpahaman) }\end{array}$ \\
\hline F.2 & Pengalaman sebelumaya dengan kontraktor utama \\
\hline F.3 & Frekuensi komunikasi \\
\hline F.4 & Kesestuaian informasi yang diterima \\
\hline \multicolumn{2}{|c|}{ Kelompok G : Waktu } \\
\hline G.1 & Jangka waktu penawaran \\
\hline G.2 & $\begin{array}{l}\text { Ketepatan waktu penyelesaian pekerjaan sesuai } \\
\text { dengan jadwal perencanaan }\end{array}$ \\
\hline G.3 & $\begin{array}{l}\text { Kesesuaian masa kerja subkontraktor dengan } \\
\text { jadwal pelaksanaan }\end{array}$ \\
\hline \multicolumn{2}{|r|}{ Kelompok H : Mutu } \\
\hline H.1 & Jaminan hasil pekerjaan sesuai mutu yang \\
\hline H.2 & Memiliki sertifikat ISO atau sejenisnya \\
\hline
\end{tabular}

\section{Pengujian Data}

Pengujian data terbagi atas uji reabilitas, uji validitas, dan analisis faktor yang meliputi pengujian KMO, pengujian Bartlett, pengujian MSA. Analisis faktor merupakan satu Teknik statistika yang dapat diguakan untuk memberikan deskripsi yang relatif sederhana melalui reduksi jumlah perubah yang disebut faktor.

\section{ANALISIS DAN PEMBAHASAN}

Pada penelitian ini data mengenai faktor-faktor yang memengaruhi kontraktor utama dalam pemilihan subkontraktor diperoleh dari kuesioner yang disebarkan pada beberapa pihak kontraktor di proyek konstruksi. Jumlah kuesioner yang disebarkan adalah sebanyak 70 dan kuesioner yang kembali sebanyak 56 kuesioner. Dari 56 kuesioner yang kembali terdapat 10 kuesioner yang tidak sesuai dengan ketentuan sehingga hanya 46 kuesioner yang dapat digunakan. 


\section{Pengujian Validitas}

Pengujian validitas dilakukan dengan pengujian KMO (Kaiser Meyer Olkin) dan Bartlett, pengujian MSA (Measure Of Sampling Adequacy) dan kemudian akan dilanjutkan pada analisa pengelompokkan faktor.

1. Pengujian KMO (Kaiser Meyer Olkin) dan Bartlett

Pada ini terdapat beberpa syarat yang harus dicapai agar dapat dilanjutkan pada analisis selanjutnya. Nilai KMO harus lebih besar dari 0.5 dan tingkat signifikansinya harus kurang dari 0.05. Hasil nilai KMO dan Baertlett dapat dilihat pada tabel 3.

Tabel 3. KMO and Bartlett's Test 1

\begin{tabular}{llr}
\hline Kaiser-Meyer-Qlkin Measure of Sampling & .662 \\
Adequacy. & & \\
Bartlett's Test of & Approx. Chi-Square & 972.706 \\
Spherisity & of & 406 \\
& Sig. & .000 \\
\hline
\end{tabular}

Pada tabel 3. dapat dilihat bahwa nilai dari KMO (Kaiser Meyer Olkin) adalah sebesar 0.662 lebih besar dari 0.5, sedangkan tingkat signifikansinya 0.000 kurang dari 0.05 sehingga semua syarat pada pengujian ini telah terpenuhi dan dapat dilakukan pada pengujian selanjutnya.

2. Pengujian MSA (Measure Of Sampling Adequacy).

Pengujian MSA (Measure Of Sampling Adequacy) ini dilakukan untuk mengetahui kevalidan dari data dimana nilai dari Anti-Image Corelation harus lebih besar dari 0.5 apabila kurang maka data tidak valid. Hasil pengujian in dapat dilihat pada tabel 4.

Tabel 4. Anti - Image Correlation 1

\begin{tabular}{|c|c|c|}
\hline Variabel & Nilai MSA & Keterangan \\
\hline A1 & $.761^{4}$ & VALID \\
\hline$A 2$ & $.468^{\circ}$ & TIDAK VALID \\
\hline A3 & $489^{4}$ & TIDAK VALID \\
\hline$A 4$ & $.548^{4}$ & VALID \\
\hline B1 & $847^{*}$ & VALID \\
\hline B2 & $393^{4}$ & TIDAK VALID \\
\hline B3 & $.794^{4}$ & VALID \\
\hline B4 & $711^{4}$ & VALD \\
\hline BS & $.494^{3}$ & TIDAK VALID \\
\hline $\mathrm{C}_{1}$ & $609^{4}$ & VALID \\
\hline $\mathrm{C} 2$ & $846^{4}$ & VALID \\
\hline $\mathrm{C} 3$ & $690^{4}$ & VALID \\
\hline D1 & $676^{\mathrm{a}}$ & VALID \\
\hline $\mathrm{D} 2$ & $631^{2}$ & VALID \\
\hline D3 & $.695^{t}$ & VALID \\
\hline D4 & $822^{4}$ & VALD \\
\hline D5 & $.793^{\circ}$ & VALD \\
\hline E1 & $368^{2}$ & TIDAK VALID \\
\hline E2 & $588^{4}$ & VALID \\
\hline E3 & $721^{\circ}$ & VALID \\
\hline $\mathrm{F} 1$ & $571^{4}$ & VALID \\
\hline$F 2$ & $688^{4}$ & VALID \\
\hline F3 & $691^{\circ}$ & VALID \\
\hline $\mathrm{F} 4$ & $839^{4}$ & VALID \\
\hline G1 & 8074 & VALID \\
\hline G2 & $651^{4}$ & VALID \\
\hline G3 & $744^{4}$ & VALID \\
\hline $\mathrm{H} 1$ & $.792^{\mathrm{b}}$ & VALID \\
\hline $\mathrm{H} 2$ & $.5855^{\circ}$ & VALID \\
\hline
\end{tabular}

Dari tabel 4 terdapat item - item yang nilai MSA kurang dari 0.5 yaitu item A2, A3, B2, B5, dan E1 sehingga item item ini tidak sesuai syarat, maka dilakukan pengujian kembali tanpa mengikut sertakan item - item tersebut.

Hasil pengujian nilai KMO dan Bartlett tanpa menggunakan item A2, A3, B2, B5, dan E1 dapat dilihat pada tabel 5. 
Tabel 5. KMO and Bartlett's Test 2

\begin{tabular}{llr}
\hline Kaiser-Meyer-Qlkin Measure of Sampling & .742 \\
Adequacy. & & \\
& Approx, Chi-Square & 747.342 \\
Bartletr's Test of & $\mathrm{df}$ & 276 \\
Spbericity. & $\mathrm{Siz}$ & .000 \\
\hline
\end{tabular}

Dari hasil pengujian kembali diperoleh nilai KMO (Kaiser Meyer Olkin) pada penelitian ini adalah sebesar 0.742 lebih besar dari 0.5 dengan tingkat signifikansinya 0.00 yakni kurang dari 0.05 , maka dilakukan pengujian MSA (Measure Of Sampling Adequacy). Hasil dari pengujian MSA (Measure Of Sampling Adequacy) tanpa item A2, A3, B2, B5, dan E1 dapat dilihat pada tabel 6.

Tabel 6. Anti - Image Correlation 2

\begin{tabular}{|c|c|c|}
\hline Variabel & Nilai MSA & Keterangan \\
\hline Al & $.744^{2}$ & VALID \\
\hline A4 & $.750^{2}$ & VALID \\
\hline B1 & $840^{3}$ & VALID \\
\hline B3 & $.703^{3}$ & VALID \\
\hline B4 & $811^{2}$ & VALID \\
\hline $\mathrm{Cl}$ & $.779^{1}$ & VALID \\
\hline $\mathrm{C} 2$ & $815^{a}$ & VALID \\
\hline $\mathrm{C3}$ & $.730^{2}$ & VALID \\
\hline D1 & $.650^{2}$ & VALID \\
\hline D2 & $.608^{a}$ & VALID \\
\hline D3 & $.689^{2}$ & VALID \\
\hline D4 & $.875^{a}$ & VALID \\
\hline D5 & $847^{a}$ & VALID \\
\hline E2 & $.497^{3}$ & TIDAK VALID \\
\hline E3 & $663^{3}$ & VALID \\
\hline F1 & $.614^{2}$ & VALID \\
\hline $\mathrm{F} 2$ & $877^{a}$ & VALID \\
\hline F3 & $.586^{2}$ & VALID \\
\hline $\mathrm{F} 4$ & $.837^{2}$ & VALID \\
\hline GI & $837^{a}$ & VALID \\
\hline $\mathrm{G} 2$ & $.818^{a}$ & VALID \\
\hline G3 & $.721^{2}$ & VALID \\
\hline $\mathrm{HI}$ & $.820^{a}$ & VALID \\
\hline $\mathrm{H} 2$ & $696^{a}$ & VALID \\
\hline
\end{tabular}

Dari tabel yang baru tersebut yakni tabel 6. diperoleh nilai dari MSA pada item E2 kurang dari 0.5 sehingga dilanjutkan pengujian ulang. Hasil pengujuan ulang KMO dan Bartlett dapat dilihat pada tabel 7.

Tabel 7. KMO and Bartlett's Test 3

\begin{tabular}{llr}
\hline Kaiser-Meyer-Olkin Measure of Sampling & 787 \\
Adequacy & & \\
Bartletrs Jest of & Approx Chi-Square & 689.970 \\
Sphericity & df & 253 \\
& Sig & .000 \\
\hline
\end{tabular}

Pada tabel tersebut nilai dari KMO dan Bartlett telah sesuai ketentuan maka dilanjutkan pada pengujian MSA. Hasil pengujian MSA dapat dilihat pada tabel 8. 
Tabel 8. Anti - Image Correlation 3

\begin{tabular}{ccc}
\hline Variabel & Nilai MSA & Keteranga \\
\hline A1 & $.744^{2}$ & VALID \\
\hline A4 & $.742^{2}$ & VALID \\
\hline B1 & $.861^{*}$ & VALID \\
\hline B3 & $.750^{2}$ & VALID \\
\hline B4 & $.801^{2}$ & VALID \\
\hline C1 & $.786^{*}$ & VALID \\
\hline C2 & $.798^{2}$ & VALID \\
\hline C3 & $.717^{2}$ & VALID \\
\hline D1 & $.699^{*}$ & VALID \\
\hline D2 & $.641^{2}$ & VALID \\
\hline D3 & $.741^{2}$ & VALID \\
\hline D4 & $.869^{*}$ & VALID \\
\hline D5 & $.866^{2}$ & VALID \\
\hline E3 & $.807^{2}$ & VALID \\
\hline F1 & $.782^{*}$ & VALID \\
\hline F2 & $.873^{2}$ & VALID \\
\hline F3 & $.675^{2}$ & VALID \\
\hline F4 & $846^{2}$ & VALID \\
\hline G1 & $.816^{2}$ & VALID \\
\hline G2 & $.809^{*}$ & VALID \\
\hline G3 & $.723^{*}$ & VALID \\
\hline H1 & $.844^{2}$ & VALID \\
\hline H2 & $.822^{*}$ & VALID \\
\hline
\end{tabular}

Pada tabel 8. yang merupakan pengujian ulang dari nilai MSA maka diperoleh nilai MSA dari setiap item telah memenuhi syarat yakni lebih besar dari 0.5. Tahap selanjutnya adalah pengujian analisis faktor.

\section{Pengujian Reliabilitas}

Pengujian ini dilakukan dengan melihat nilai dari cronbach's alpha. Nilai dari cronbach's alpha pada penelitian ini dapat dilihat pada tabel 9.

Tabel 9. Reliability Statistics

\begin{tabular}{|c|c|c|}
\hline $\begin{array}{l}\text { Cronback's } \\
\text { Alpba }\end{array}$ & $\begin{array}{c}\text { Cronback's } \\
\text { Alpba Based } \\
\text { on } \\
\text { Standardized } \\
\text { Items. }\end{array}$ & $\begin{array}{l}\mathrm{N} \text { of } \\
\text { Items. }\end{array}$ \\
\hline .919 & .921 & 23 \\
\hline
\end{tabular}

Pada tabel 9. tersebut diperoleh nilai cronbach's alpha adalah sebesar 0.919 dan berdasarkan pada tabel nilai cronbach's alpha pada tabel 3.3 maka data kuesioner ini termasuk reliabel. Maka dilanjutkan dengan analisis faktor, dan nilai cronbach's alpha setiap item dapat dilihat pada tabel 10. 
Tabel 10. Item-Total Statistics

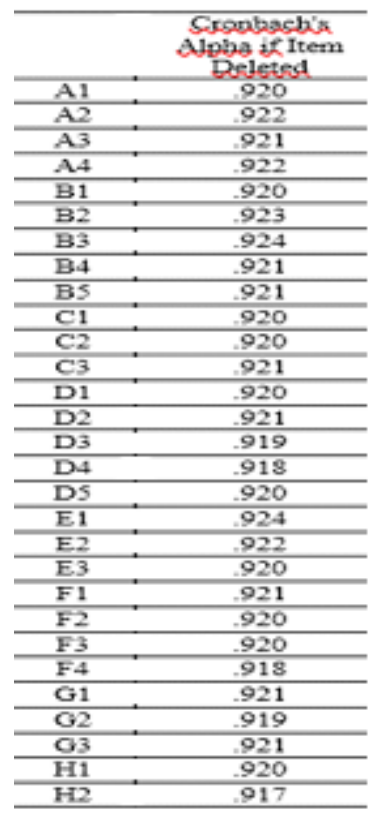

\section{Pengelompokkan Faktor Utama}

Ketentuan pengelompokkan faktor dilihat dari total pada setiap item yakni total item harus lebih dari 1. Nilai total dari setiap item dapat dilihat pada tabel 10. Dimana pada tabel tersebut diperoleh 6 (enam) item yang memiliki total lebih dari 1 dan jumlah kumulatifnya adalah sebesar 80.240 \%. Sehingga pada penelitian ini diperoleh 6 (enam) kelompok faktor, dan dapat dilihat pada tabel 11.

Tabel 11. Initial Eigenvalues

\begin{tabular}{|c|c|c|c|}
\hline \multirow[b]{2}{*}{ Comeconent } & \multicolumn{3}{|c|}{ Initial Eigensulys } \\
\hline & Total & $\begin{array}{c}\% \text { of } \\
\text { Vinatec }\end{array}$ & $\begin{array}{c}\text { Corrolatixe } \\
\% \%\end{array}$ \\
\hline 1 & 8.685 & 37.760 & 37.760 \\
\hline 2 & 2.569 & 11.170 & 48.930 \\
\hline 3 & 1.992 & 8.660 & 57.590 \\
\hline 4 & 1.736 & 7548 & 65.138 \\
\hline 5 & 1.342 & 5.835 & 70.973 \\
\hline 6 & 1.034 & 4.497 & 75.470 \\
\hline 7 & .859 & 3.736 & 79.206 \\
\hline 8 & .712 & 3.094 & 82.300 \\
\hline 9 & .394 & 2582 & 84.882 \\
\hline 10 & .544 & 2.365 & 87247 \\
\hline 11 & 477 & 2074 & 89.321 \\
\hline 12 & .397 & 1.728 & 91.049 \\
\hline 13 & .365 & 1.588 & 92.637 \\
\hline 14 & 339 & 1.475 & 94.112 \\
\hline 15 & .287 & 1.249 & 95.361 \\
\hline 16 & 257 & 1.119 & 96.480 \\
\hline 17 & .187 & $\$ 15$ & 97.295 \\
\hline 18 & .158 & .686 & 97.981 \\
\hline 19 & .128 & .559 & 98.539 \\
\hline 20 & .108 & .472 & 99.011 \\
\hline 21 & .099 & .428 & 99,439 \\
\hline 22 & .069 & .300 & 99.739 \\
\hline 23 & .060 & .261 & 100.000 \\
\hline
\end{tabular}

\section{Pembagian Kelompok - Kelompok Faktor}

Pembagian kelompok faktor dapat dilihat pada tabel 4.9. Rotated Component Matrix. Dari tabel tersebut pemilihan kelompok item dilihat dari nilai korelasi yang terbesar dengan setiap faktor. Contohnya pada item C2 memiliki korelasi sebesar 0.885 dengan faktor 1, 0.122 dengan faktor 2, 0.006 dengan faktor 3, 0.145 dengan faktor 4, -0.098 
dengan faktor 5 dan 0.228 dengan faktor 6, maka item C2 masuk pada kelompok faktor 6. Untuk lebih jelas dapat dilihat pada tabel 12 .

Tabel 12. Rotated Component Matrix ${ }^{a}$

\begin{tabular}{lcccccc}
\hline & \multicolumn{7}{c}{ Component } \\
\cline { 2 - 6 } & 1 & 2 & 3 & 4 & 5 & 6 \\
\hline G3 & .856 & .050 & .212 & .018 & .122 & .018 \\
H1 & .835 & .281 & -.062 & .108 & .032 & .032 \\
G2 & .823 & .213 & .162 & .102 & .233 & .162 \\
D4 & .701 & .307 & .381 & .155 & -.188 & .152 \\
F1 & .614 & .028 & .013 & .516 & .189 & .078 \\
C2 & .079 & .819 & .126 & .035 & -.097 & .404 \\
C1 & .045 & .717 & .112 & .228 & -.059 & .385 \\
D5 & .249 & .699 & .052 & .278 & -.123 & .113 \\
H2 & .432 & .678 & .210 & .148 & -.157 & -.027 \\
F2 & .097 & .637 & .117 & .492 & .333 & .007 \\
A1 & .341 & .453 & .337 & -.111 & .299 & .262 \\
D2 & .203 & .035 & .856 & -.013 & -.047 & .175 \\
D3 & .185 & .124 & .815 & .150 & .059 & .312 \\
D1 & .029 & .326 & .809 & .216 & -.069 & -.129 \\
F3 & .014 & .330 & .065 & .866 & .044 & .026 \\
F4 & .334 & .369 & .084 & .641 & .057 & .259 \\
B4 & .099 & .116 & .253 & .595 & -.558 & .158 \\
E3 & .469 & -.085 & .289 & .495 & -.167 & .212 \\
B3 & .317 & -.097 & .034 & .069 & .772 & .147 \\
G1 & .195 & .520 & .252 & .110 & .537 & .036 \\
C3 & .008 & .272 & .134 & .211 & .038 & .826 \\
B1 & .392 & .296 & .188 & .031 & -.049 & .592 \\
A4 & .175 & .159 & .268 & .134 & -.618 & .416 \\
\hline
\end{tabular}

Dibawah ini merupakan pengelompokkan dari item-item variabel:

a. Kelompok Faktor 1

1. Kesesuaian masa kerja subkontraktor dengan jadwal pelaksanaan (G3)

2. Jaminan hasil pekerjaan sesuai mutu yang ditetapkan (H1)

3. Ketepatan waktu penyelesaian pekerjaan sesuai dengan jadwal perencanaan (G2)

4. Mengutamakan keamanan dan keselamatan kerja selama pelaksanaan proyek konstruksi (D4)

5. Komunikasi yang Baik (F1)

b. Kelompok Faktor 2

1. Lama pengalaman melaksanakan proyek serupa (C2)

2. Prestasi melaksanakan proyek (C1)

3. Metode Kerja (D5)

4. Memiliki sertifikat ISO atau sejenisnya (H2)

5. Pengalaman sebelumnya dengan kontraktor utama (F2)

6. Data dan informasi perusahaan (A1)

c. Kelompok Faktor 3

1. Sumber daya yang dimiliki (D2)

2. Memiliki peralatan dan fasilitas yang sesuai standar (D3)

3. Keahlian personil (D1)

d. Kelompok Faktor 4

1. Frekuensi komunikasi (F3)

2. Kesesuaian informasi yang diterima (F4)

3. Struktur Organisasi (B4)

4. Adanya jaminan asuransi terhadap pekerja (E3)

e. Kelompok Faktor 5

1. Harga penawaran yang kompetitif (B3)

2. Jangka waktu Penawaran (G1)

f. Kelompok Faktor 6

1. Lamanya hubungan kerjasama yang terjalin (C3)

2. Jenis penawaran (B1)

3. Keanggotaan dalam asosiasi konstruksi (A4)

4. Memiliki peralatan dan fasilitas yang sesuai standar (D3) 


\section{KESIMPULAN}

1. Faktor - faktor yang memengaruhi pemilihan subkontraktor adalah sebagai berikut :

a. Kelompok faktor 1: Kinerja Perusahaan

1) Kesesuaian masa kerja subkontraktor dengan jadwal pelaksanaan

2) Jaminan hasil pekerjaan sesuai mutu yang ditetapkan

3) Ketepatan waktu penyelesaian pekerjaan sesuai dengan jadwal perencanaan

4) Mengutamakan keamanan dan keselamatan kerja selama pelaksanaan proyek konstruksi

5) Komunikasi yang baik

b. Kelompok faktor 2: Prestasi Perusahaan

1) Lama pengalaman melaksanakan proyek serupa

2) Prestasi melaksanakan proyek

3) Metode Kerja

4) Memiliki sertifikat ISO atau sejenisnya

5) Pengalaman sebelumnya dengan kontraktor utama

6) Data dan informasi perusahaan

c. Kelompok faktor 3: Sumber daya

1) Sumber daya yang dimiliki

2) Memiliki peralatan dan fasilitas yang sesuai standar

3) Keahlian personil

d. Kelompok faktor 4: Informasi

1) Frekuensi komunikasi

2) Kesesuaian informasi yang diterima

3) Struktur Organisasi

4) Adanya jaminan asuransi terhadap pekerja

e. Kelompok faktor 5: Marketing

1) Harga penawaran yang kompetitif

2) Jangka waktu Penawaran

f. Kelompok faktor 6: Hubungan kerjasama

1) Lamanya hubungan kerjasama yang terjalin

2) Jenis penawaran

3) Keanggotaan dalam asosiasi konstruksi

2. Berdasarkan analisis diperoleh 6 faktor yang paling memengaruhi dalam pemilihan subkontraktor dari setiap kelompok faktor, yaitu: kesesuaian masa kerja subkontraktor dengan jadwal pelaksanaan, lama pengalaman melaksanakan proyek serupa, sumber daya yang dimiliki, frekuensi Komunikasi, harga penawaran yang kompetitif dan lamanya hubungan kerjasama yang terjalin.

\section{DAFTAR PUSTAKA}

Andri. (2016). Analisis Faktor - Faktor Yang Mempengaruhi Waktu Tunggu Pengadaan Material Beton Pada Beberapa Proyek Di Jakarta. Skripsi. Jakarta : Universitas Tarumanagara.

Binus, Universitas. (2015). Analisis Faktor. [Online], [https://sbm.binus.ac.id/2015/11/21/analisis-faktor/, diakses tanggal 12 Juli 2018]

Dewanata, T.P. (2016). Analisis Faktor Dominan Keterlambatan Waktu Mulai Proyek Konstuksi dari Sudut Pandang Pengguna Jasa. Skripsi. Jakarta : Universitas Tarumanagara.

Ervianto, W. (2005). Manajemen Proyek Konstruksi (Edisi Revisi). Yogyakarta: Andi.

Hartman, A. 2009. "Relative importance of subcontractor selection criteria: evidence from Singapore”. Journal of Constraction Engineering and Management.

Hendriko. (2016). Analisis Faktor - Faktor Dalam ISO 9001 : 2008 Yang Berpengaruh Terhadap Kinerja Karyawan Pada Kontraktor Proyek Apartemen High Rise Di Jakarta. Skripsi. Jakarta : Universitas Tarumanagara.

Herlambang, B. (2017). Analisis Faktor Keberhasilan Kontraktor Dalam Mengikuti E-Procurement Di Jakarta. Skripsi. Jakarta : Universitas Tarumanagara.

Lavelle, Derek, Henry, Jason dan Steel, Glenn. (2007). The Selection of Subcontraktors: Is Price The Major Factor?. Annual ARCOM Conference. Belfast: UK.

Logawa, G. (2007). Manajemen Proyek Konstruksi. Jakarta: Universitas Trisakti.

Luu, D. T. dan Sher, W. (2006). "Construction tender subcontract selection using case-based reasoning”. The Australian Journal of Construction Economics and Building. Vol. 6. No. 21. 
Maitimu, J., Rachmansyah, A., dan Pujiraharjo, A. (2014). Faktor-Faktor yang Mempengaruhi Kepercayaan Kerjasama Antara Kontraktor dan Sub Kontraktor di Kota Ambon. Jurnal Spectra. Vol. 12. No. 23 (Januari 2014): 84-94.

Messah. Yunita A, Krinsnayanti, Denik S, Pono, Rohi D Radja. (2012). Kajian Kriteria Pemilihan Subkontraktor Oleh Kontraktor Utama Dengan Menggunakan Metode Analytic Hierarchy Process (AHP). Kupang: Universitas Nusa Cendana.

Rasono, J.B. (2017). Proses Kualifikasi dan Evaluasi Subkontraktor pada Proyek EPC. [Online]. [https://rasono.wordpress.com/, diakses tanggal 25 Februari 2018]

Resmal, D. (2014). Faktor-Faktor yang Dipertimbangkan Kontraktor Dalam Memilih Subkontraktor pada Pelaksanaan Proyek Konstruksi. Skripsi. Banda Aceh : Universitas Syiah Kuala Darussalam.

Saputra, et.al. (2017). Pengaruh Komunikasi Terhadap Keberhasilan Proyek Pada Hubungan Kerja Antara Kontraktor dan Subkontraktor. Jurnal Sains Terapan. Vol. 3 No. 2.

Simanjuntak, M.R.A., Widjajakusuma, J., dan Tantri, N. (2009). Analisis Faktor yang Mempengaruhi Keputusan Kontraktor dalam Pemilihan Kontraktor Spesialis Terhadap Peningkatan Kinerja Procurement Pada Proyek Jalan Lokal di Kalimantan Timur. Konferensi Nasional Teknik Sipil 3. Jakarta: Indonesia.

Sipil, Guru. (2017). Pengertian dan Tugas Konsultan Pengawas Proyek. [Online]. [https://www.gurusipil.com/konsultan-pengawas/, diakses tanggal 18 Mei 2018].

Sipil. Guru. (2017). Pengertian dan Tugas Kontraktor Pelaksana Proyek. [Online]. [https://www.gurusipil.com/pelaksana-contractor/, diakses tanggal 18 Mei 2018].

Soeharto, I. (1992). Manajemen Proyek Industri. Jakarta: Erlangga.

Tjuaja, C.T. (2017). Analisis Faktor Faktor Keterlambatan Waktu Pada Pekerjaan Struktur pada Proyek Konstruksi. Skripsi. Jakarta : Universitas Tarumanagara.

Zulaihah, L. dan Patria, R. (2016). "Pemilihan Subkontraktor PT X dengan Metode Analytical Hierarchy Process”. Jurnal Bina Teknika. Vol. 12. No. 1 (Juni 2015): 95-102. 
